\title{
As di-versões visíveis das imagens infantis
}

Gianfranco Staccioli ${ }^{*}$

Resumo: No presente artigo desenvolvem-se análises sobre a complexidade da representação gráfica pelas crianças, em especial as pequenas. Os desenhos de meninos e meninas são abordados em sua riqueza como metáforas visuais que propóem a curiosidade, a indagação, diferentes formas de compreensão e relação com os traçados, com suas cores e formas. Consideram-se diferentes elementos que, entrelaçados, dão a conhecer os meninos e meninas desenhistas e seus desenhos de modo abrangente. Propóe a todos que entrem em contato com os desenhos que não pr ocurem respostas apressadas, mas que diante deles, é preciso pensar, num tempo mais lento em que a reflexão e o estar junto sejam contemplados.

Palavras-chave: desenhos; infâncias; metáfora visual; arte.

\section{The visible diversions of children's images}

Abstract: In the present article analyses are carried out regarding the complex graphic representations made by children, especially the small ones. The boys and girls' drawings are analysed in their richness as visual metaphors which propose curiosity, questioning, different ways of understanding and the relationship with the traces and their colors and shapes. Distinct elements are considered which, intertwinned, reveal the young designers and their drawings comprehensively. It proposes all the ones who are in contact with the drawings not to look for fast answers, but faced by them to think, more slowly, for the reflection and this closeness to be contemplated.

Key words: drawings; childhoods; visual metaphor; art.

\section{I - Imagens di-vertidas}

As representações gráficas infantis são produtos complexos. Durante muito tempo pensou-se que os desenhos das crianças fossem uma produção "espontânea" que reproduzia um mundo criado pela fantasia delas, na trilha das "lembranças do mundo real”. Não foi por acaso que, na Itália, a introdução do desenho nos programas da escola primária ocorreu em 1923, como proposta do filósofo idealista, Giovanni Gentile, e se chamava, justamente, "desenho espontâneo". Uma espontaneidade

\footnotetext{
* Universidade de Florença, Secretário Nacional dos CEMEA italianos (Centros de Exercitação dos Métodos da Educação Ativa), Itália. gstaccioli@unifi.it

Tradução: Regina Célia da Silva. Revisão técnica: Marcia Gobbi
} 
que fazia entrever uma força "natural" infantil, mesmo "ingênua", que aparecia ligada ao trabalho dos artistas e da arte adulta. O primeiro grande estudo sobre o assunto foi publicado na Itália em 1887, organizado por Corrado Ricci ${ }^{1}$ diretor de grandes museus como o Brera, de Milano, e o Uffizi, de Florença, onde se fala justamente em "arte infantil". Mesmo muitos estudos posteriores são relacionados a uma ideia de sucessão "natural", que identifica também a presença de "estágios" que se seguem durante o desenvolvimento e que têm características específicas e reconhecíveis. As quatro fases indicadas em 1927 por Georges-Henri Luquet ${ }^{2}$ são conhecidas ${ }^{3}$, até porque elas pareceram convincentes para Piaget, que sustentou a correspondência entre a evolução do desenho e o desenvolvimento intelectual, e foram a base daquelas que foram definidas como "teorias dos estágios".

O impulso natural para desenhar e a transformação das imagens que ocorrem durante o crescimento das crianças não está em discussão. As crianças, desde que tenham a possibilidade, sempre tentam desenhar e fazer imagens. E suas tentativas tiveram desde sempre mudanças ligadas à experiência, ao conhecimento, à variação da sensibilidade, embora certas semelhanças com a arte adulta sejam indiscutíveis, sendo necessário, de qualquer modo, ter cautela em estabelecer uma relação de semelhança mais ligada ao processo do que à representação acabada. As crianças não são artistas, mas muitas vezes agem como artistas conforme a feliz definição de Francesco De Bartolomeis 4 . Não por acaso muitos estudos do final dos anos 1970 concentraram-se em "processos" sobre como as crianças construíam suas representaçôes (o que era desenhado antes e depois, em qual posição as figuras eram dispostas, se a representação era da direita para a esquerda ou vice-versa, etc.).

A complexidade das representações infantis não é dada apenas pelo fato de estar ligada a impulsos profundos, a variações em função da idade ou de procedimentos gráficos. Há outros elementos que aparecem entrelaçados e que se referem tanto à pessoa que desenha (à sua pessoa, ao seu mundo interior), quanto às competências técnicas de representação (ao conhecimento dos instrumentos úteis para a representação). A primeira dimensão, mais psicológica, foi e é mais explorada: são provas disso os muitos testes centrados na figura humana ou as solicitaçôes de representação de eventos específicos ("desenhe um amigo", "represente a sua casa", "a sua sombra", etc.) ou aqueles ligados à relação entre cor e personalidade. A segunda dimensão, mais didática, foi objeto de atenção, sobretudo por parte

I. L'arte dei bambini, Zanichelli, Bolonha, 1959.

2. Il disegno infantile (trad. it.), Armando, Roma, 1969.

3. Luquet indica uma primeira fase de representação (2-3 anos) que define "realismo fortuito" $\notin$; uma segunda (entre 3 e 4 anos) chamada "realismo falhado"; uma terceira, "realismo intelectual" (5-6 anos) e, enfim, uma que se chama "realismo visual" (8-9 anos). Piaget retoma essas fases, falando também da evolução das noções espaciais. In: J. Piaget; B. Inhelder, La rapresentation de l'éspace dans l'enfant, P.U.F., Paris, 1947.

4. Girare intorno all'arte: valutare e produrre, La Nuova Italia, Firenze, 1990. 
de educadores e pedagogos, e dizia respeito tanto à intimidade com a técnica (aprendizagem dos efeitos decorrentes do uso do pincel, das cores, da noção de perspectiva, etc.) quanto à criação de contextos comunicativos estimulantes. A complexidade das representações infantis é dada também pelo fato de que a relação entre o aspecto visual da imagem produzida e a elaboração dela não é transparente: o desenho muda à medida que é desenhado, não apenas nos detalhes, mas, muitas vezes, também na sua inteireza. Uma criança que inicia um desenho pode ter um projeto, uma ideia inicial. Ao mesmo tempo, não se sente obrigada a ter que manter o ponto de partida inicial. Se durante a elaboração do desenho, um signo gráfico, uma cor, um estímulo externo, oferecem-lhe uma sugestão diferente, eles podem tornar-se um caminho a ser percorrido, uma pista a ser explorada, um itinerário para um novo prazer e uma "diversão". Diversão e prazer são molas propulsoras de experiências, também gráficas, para as crianças. Como nos lembra John Dewey ${ }^{5}$ a experiência não é só um fazer, mas o fazer que se vincula ao pensar, o fazer que se volta sobre si mesmo e que produz um novo fazer, num continuum sem fim. Uma experiência torna-se de qualidade quando apresenta duas características, diz ainda Dewey: "se é lúdica e se está inserida num 'continuum experimental"”. Experimentar e divertir-se, no sentido de di-verter, de voltar o olhar para outro lugar, descobrindo outras perspectivas, outros modos de raciocinar, indo além dos esquemas e dos modelos adquiridos. Por isso, a complexidade dos desenhos infantis é dada também pelo fato de que o que aparece na folha não é outra coisa a não ser a pálida imagem de um projeto mais elaborado, articulado, profundo, que di-verte continuamente.

Com essas premissas, talvez seja possível aproximar-se das representações gráficas das crianças, não para encontrar uma explicação para as formas e para as cores de suas obras, mas para experimentar mergulhar no mundo invisível de seu pensamento, que, através da imagem gráfica, tornou-se visível e que pode ajudarnos a entrar na complexidade da mente do autor.

\section{2 - Pensamentos visíveis}

Olhar desenhos de crianças, aproximar-se de seus pensamentos visíveis é também entrar na "consciência representativa da realidade". Muito se discutiu sobre se as crianças desenham o que veem, o que conhecem, o que pensam ${ }^{6}$. Conhecer

5. 1949, Esperienza e educazione (trad. it.), La Nuova Italia, Firenze, 1973.

6. Piaget parece convencido de que as crianças desenham o que conhecem (cf. J. Piaget; B. Inhelder, La psycologie de l'enfant, P.U.F. Paris, 1966), enquanto Rudolf Arnheim sustenta que as crianças desenham o que veem e o fazem através de "uma lógica admirável com a qual adaptam as suas configurações às condições impostas por um meio bidimensional" (R. Harnheim, Art and visual perception: a Psycology of the creativite eye, by the Regents of the University of California, 1974 (1954). 
e representar a realidade (própria dos outros e das coisas) está no trabalho com as imagens que as crianças fazem desde muito pequenas, desde os primeiros traçados, das primeiras garatujas, das primeiras composiçōes. Para muitos adultos, muitas vezes, conhecer é ainda sinônimo de significação, de denominação, e, no desenho, é sinônimo de figuração; se uma criança desenha um cachorro - pensamos - quer dizer que conhece um cachorro. Se depois o desenha "bem" (verossímil, com quatro patas, com rabo e com todos os outros atributos), quer dizer que o conhece bastante bem. Daí a ideia de que um desenho cuidado, rico em detalhes e verossímil seja sinônimo de competência. É como se nós tivéssemos na cabeça um mundo cuidado, exato, fotografável, estático.

Quando a criança o representa assim, muitos adultos parecem contentes. A verossimilhança faz pensar que aquela criança aprendeu como é feito o mundo que representa. É uma pena também que esse modo de pensar não corresponda a uma perspectiva endógena (a pessoa se constrói a partir das suas elaborações internas) e construtivista (a realidade não é dada, mas construída gradativamente, através de estruturas cognitivas peculiares). $\mathrm{O}$ construtivismo (que é uma corrente de pensamento à qual muitos hoje se referem)

parte da complexidade e da ambiguidade dos conceitos de realidade e conhecimento, evidenciando como a realidade e o mundo exterior precisam ser interpretados essencialmente como fenômenos experienciados... não existe nenhum sujeito separado da realidade, tampouco nenhuma realidade pré-existente à ação do conhecimento, uma vez que é esta última que a constrói; de forma que a realidade não é única e dada objetivamente, recursivamente conexa ao sujeito que continuamente a define. ${ }^{7}$

Se assim for, então a representação fotográfica de um cachorro não garante que tenha ocorrido a consciência "construída" de um cachorro por parte de uma criança. Dá-nos apenas a garantia do fato de que a criança tem competências técnicas para nomear e representar conforme um modelo canônico de cachorro. Pena que esse modo de pensar não corresponda nem à experiência do pobre antiquário Bodoni descrito em um dos romances de Umberto $\mathrm{Eco}^{8}$. Giambattista Bodoni volta do coma, tendo perdido a memória. Na verdade, consegue lembrar-se, mas só do que se refere à sua memória semântica, à sua memória "pública" (datas, eventos, noçôes aprendidas...), que é - para as neurociências - uma memória explícita "aquela pela qual se sabe que uma andorinha é um pássaro e que os pássaros voam e têm penas...”. Mas Bodoni não se lembra de nada da sua memória autobiográfica, aquela

7. Ceruti M., La danza che crea, Feltrinelli, Milano, 1989.

8. U. Eco, La misteriosa fiamma della regina Loana, Bompiani, Milano, 2004. 
que lhe permite reconhecer a mulher e os filhos ou se lembrar do perfume de uma flor, aquela memória que permite conectar os episódios com base no vivido, na experiência pessoal, que permite estabelecer um nexo entre hoje e ontem, entre as coisas "públicas" e aquelas percebidas. Saber desenhar cachorros de maneira "pública" (e um pouco estereotipada) não é o mesmo que saber desenhá-los de maneira autobiográfica.

Portanto, se é o sujeito que tem a tarefa de definir e redefinir constantemente a realidade segundo as suas "memórias", o nosso cachorro terá que ser redefinido a cada vez, de acordo com as elaborações cognitivas que o desenhista estiver prestes a comunicar. Um cachorro que corre pode ter oito patas (como nas pinturas do futurista Balla), um cachorro mal-cheiroso será diferente de um cachorro que dá medo, ou de um cachorro afetuoso... Enfim, os cachorros possíveis e visíveis tornam-se tantos, alguns podem ser mostrados simulando uma imagem fotográfica, outros (muitos outros) não. Quem elabora a imagem é obrigado a descobrir caminhos próprios, tem que encontrar alguma solução que antes não havia (ou seja, inovadora, divergente, personalizada e por isso mesmo di-vertida), tem que construir des-construindo a realidade. As representações possíveis são como os pensamentos: podem ser um número imprevisível, podem misturar-se e entrelaçar-se entre si, podem encontrar soluções banais ou criativas... os desenhos das crianças são "pensamentos visuais", o que coloca o problema da sua leitura, da sua compreensão, do seu acolhimento (e acolher não quer dizer apenas aceitar ou permitir).

Entre considerar um desenho como uma "representação da realidade" ou considerá-lo como um "pensamento visual" há muita diferença. No primeiro caso, prevalece o critério da verossimilhança; no segundo, o da elaboração. A verossimilhança todos nós sabemos "ler"; quanto à elaboração, conseguimos compreender um pouco menos. E é natural que seja assim, porque o conhecimento que encontra forma nas representações infantis (e também naquela dos artistas) é ambíguo e complexo (como já se disse: "o construtivismo parte da complexidade e da ambiguidade dos conceitos de realidade e de conhecimento").

Qual é a "história" na produção de Massimo? A sua imagem narrativa conta fatos numa sucessão simultânea. Massimo, ao usar uma folha já traçada (um adulto, por cujo motivo não sabemos, havia desenhado um triângulo com uma linha longa na base) explica que "É um senhor que vai ao mercado... Tem muitos pés, para caminhar rápido... tem que comprar tantas coisas... pensa... na cabeça... compra de tudo... depois come... come começando das coisas maiores para as menores... dá para ver até o estômago... Depois dá uma escovadinha nos dentes”... Sua história apresenta elaborações interessantes: para mostrar que o homem caminha rápido põe mais pernas; os pensamentos são visíveis na cabeça e se prolongam pelo espaço, os eventos são simultaneamente visíveis... 


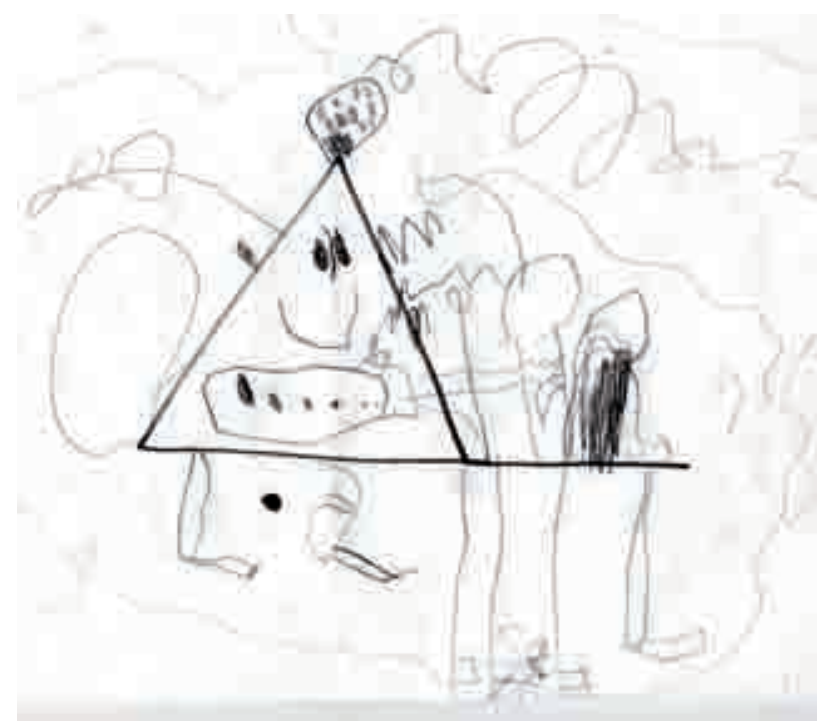

Fig. I - Massimo (5 anos): O senhor que vai ao mercado

Que vibrações terão percorrido Caterina (4 anos) enquanto "desenhava" aquelas linhas enroladas? Estava pensando num pato voador? Ou na vovó em sua cadeira de balanço? Ou são linhas imaginárias que ligam a uma constelação? É possível saber? E, sobretudo, para que serve saber?

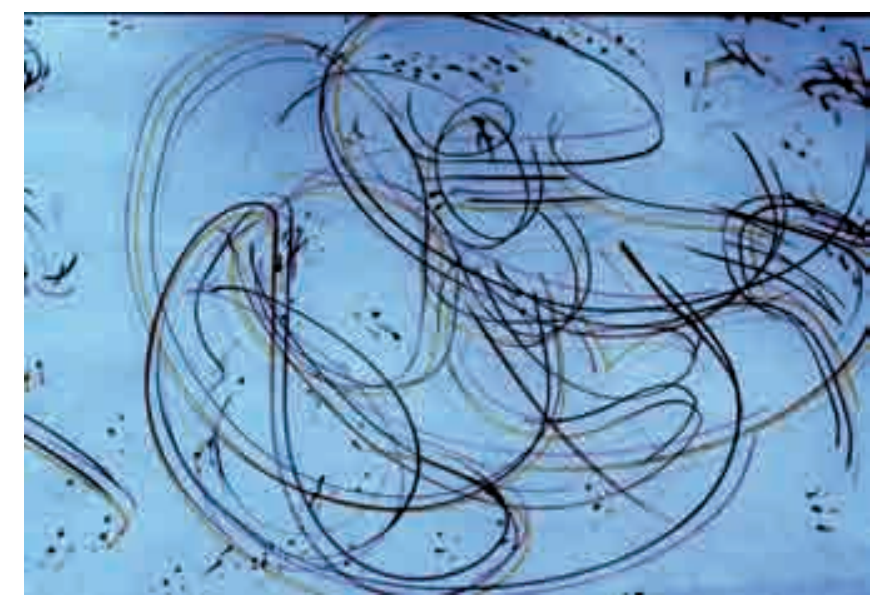

Fig. 2 - Caterina (4 anos): Signos que se movem 
Um adulto que vê uma "produção" só pode se sentir meio perdido, inadequado, diante de alguns desenhos das crianças. As dificuldades de compreensão são um fato verdadeiro, ainda mais porque nem sempre as crianças desenham para contar personagens ou episódios. Às vezes, o desenho caracteriza-se por um desejo de experimentar "o que acontece se..." e então - talvez - aconteça como aconteceu com Luca, que furou a folha com um objeto pontiagudo. Poderíamos dizer que o desenho de Luca ( 5 anos) "atravessa a folha e se projeta no pano de fundo colorido da natureza". A frase entre vírgulas poderia ter sido escrita por um crítico de arte para ilustrar um trabalho de Lucio Fontana, o artista toscano que perfurava as próprias telas. A intenção de Luca era - mais simplesmente - talvez "ver o que acontece se..." se faz um desenho furando uma folha. As imagens serão reconhecidas? As coisas serão vistas perfuradas através dos furos? Que cores vão aparecer quando olhamos o papel contra a luz? E quando a folha se move, o que acontece?"... Luca não se preocupou muito em "contar". Fez mais ou menos a mesma coisa repetidas vezes (um sol?) e obteve um conjunto até agradável de se ver. O desenho furado depois foi chamado: "estrelas no céu".

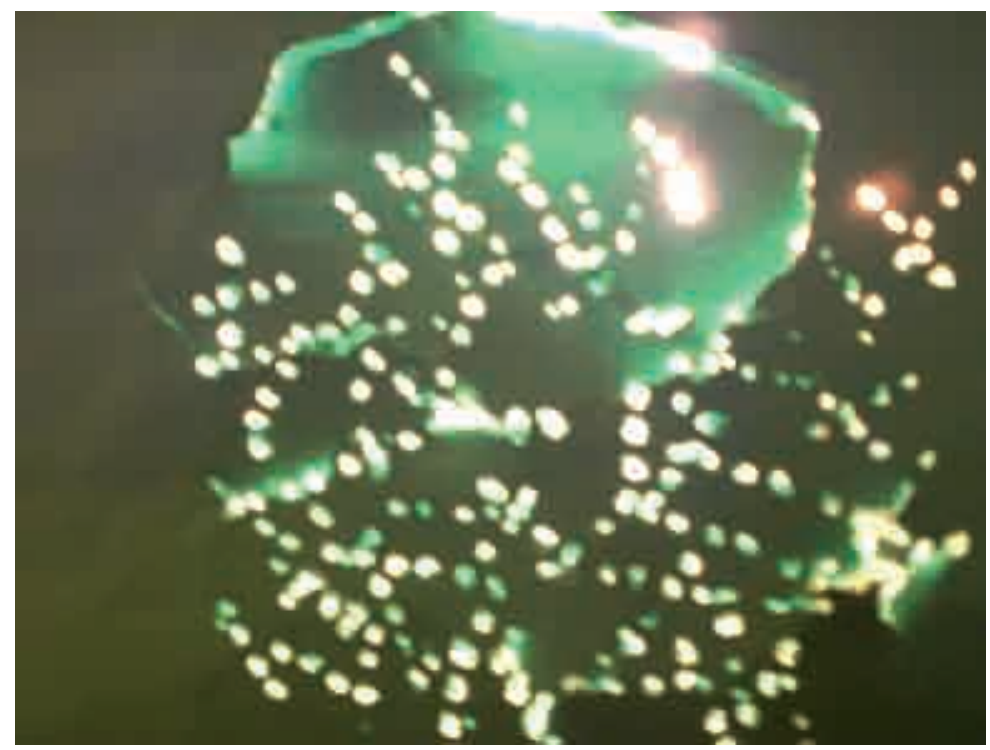

Fig. 3 - Luca (5 anos): Estrela num céu verde

Às vezes o desenho é uma desculpa para brincar de enfeitar, como este trabalho de Katia que mostra as colinas de Crevalcuore (Emilia, Itália) com colorações não realistas, mas de que ela "gosta muito". 


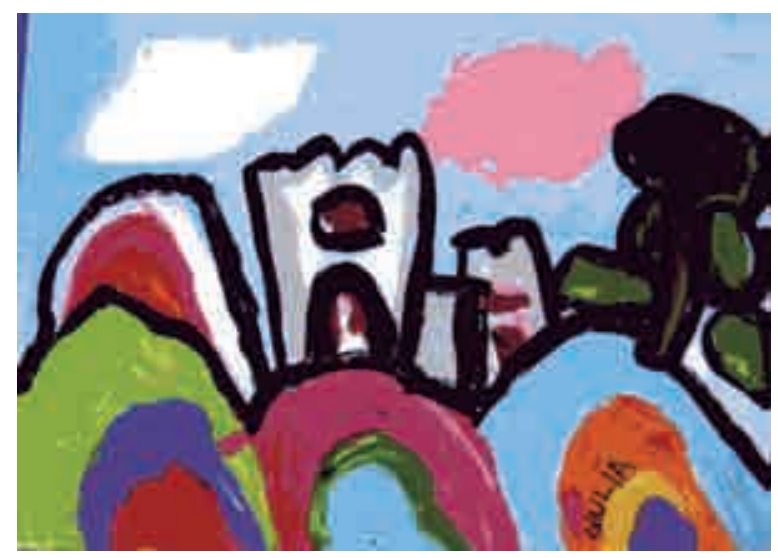

Fig. 4 - Katia (5 anos): As colinas de Crevalcuore

Outras vezes é a busca cromática ou a análise de certo número de detalhes que se tornam o objetivo-pesquisa comunicativa do desenhista. O dragão de Massimo é um desenho não completo, interrompido. Mas a sua construção gráfica durou muito, porque cada detalhe que desenhava era "explicado" à colega que desenhava ao seu lado. Cada parte do dragão é uma história em si, constituída de materiais e funções diferentes. Poderíamos raciocinar sobre o aspecto gráfico da composição ou sobre a relação entre espaços vazios e cheios, sobre o peso das cores... Obviamente tudo isso não está nas intenções explícitas de Massimo, mas são todos aspectos interessantes de serem ressaltados.

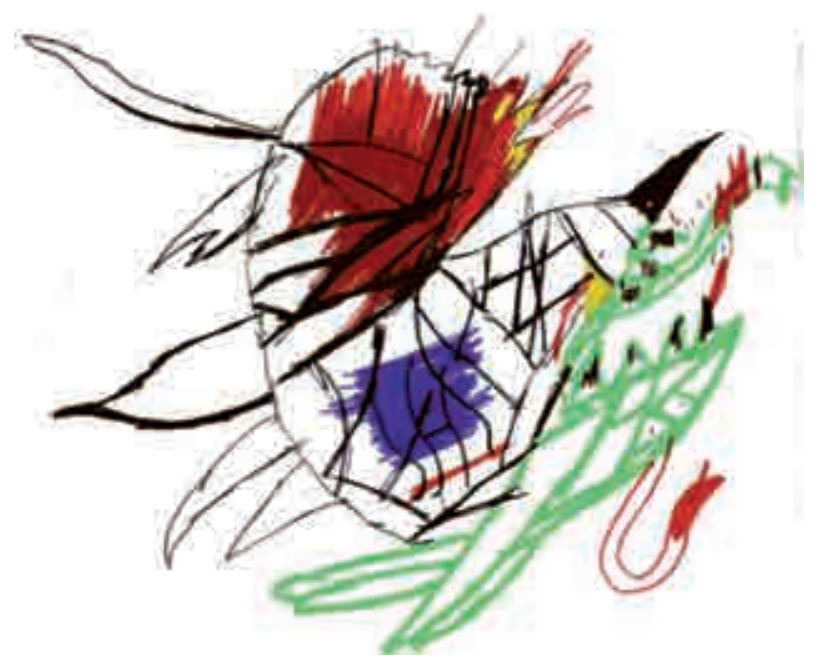

Fig. 5 - Massimo (5 anos): 0 dragão 
E, em seguida, são os estilos pessoais que tornam ainda mais difícil (e interessante) a leitura de um desenho. $\mathrm{O}$ mesmo cachorro representado por uma criança que tem um estilo "visual" não é igual àquele desenhado por uma criança "táctil"; o cachorro feito por um desenhista "dramatists" não é o mesmo que aquele representado por uma criança que "olha" as coisas e que ama os detalhes de um evento ou que "vive" a realidade, ou que "enfeita" a realidade, para usar uma classificação diferente dos estilos representativos ${ }^{10}$. Olhar um desenho de uma criança como uma "produção" é, sem dúvida, algo incerto e difícil. Mas não há outro caminho. O desenho é certamente expressão da personalidade (deixamos aos psicólogos a interpretação); é, com certeza, expressão de um tipo de conhecimento (o de nomear); é uma demonstração de gosto estético (aqui também: com quais critérios se avalia o gosto?); mas é, sobretudo, um "pensamento visual", elaboração que requer escuta, imagem interpretativa, que requer uma outra interpretação, figura imprecisa que não requer precisão. Quando não se entende, é melhor renunciar ao julgamento. E não vale a regra do "explica para mim o que você fez". Nem sempre as crianças sabem responder a essa pergunta; assim como tantos artistas que responderam ao mesmo quesito com um: "Não sei". Outros artistas deixaram interdito o espectador, confessando que o que tinham feito era em parte desconhecido para eles mesmos:

"Se na minha pintura há algo de humorístico, eu não busquei isso de forma consciente" (Joan Mirò). As crianças não são artistas, mas suas "elaboraçōes" são construções fecundas de pensamento e de emoção. Neste sentido são como o quadro de um artista, pelo menos segundo Joan Mirò: "o quadro tem que ser fecundo. Tem que fazer nascer um mundo. Pouco importa se representa flores, personagens, cavalos; o importante é que revele um mundo, algo vivo. Dois mais dois não são quatro. São quatro apenas para os contadores"11.

\section{3 - As crianças não são criativas}

As crianças não são artistas e nem são criativas. Desde muito pequenas elas também absorvem a cultura que as rodeia, tentam imitar o que fazem os adultos, buscam compreensão e afeto, estão dispostas a tudo para se parecerem conosco ou fazer como nós, adultos. Nós, em troca, oferecemo-lhes modelos, certezas,

9. Classificação proposta por Lowenfeld V.; Brittain W. L. (1939); La natura dell'attività creatrice (trad. it.), Giunti, Firenze, 1968.

10. Staccioli G., Immagini fatte ad arte; Carocci, Roma 2005; Staccioli G., Progettare immagini, La Nuova Italia, Florença, 1995.

1।. Mirò J., Le metamorfosi di una forma, ArtificioSkira, Milano, 1999. 
muitas vezes aparentes; dizemos a elas como devem se comportar, como se vestir, como se deveria brincar, como podem se relacionar com os outros; damos a elas uma ideia das regras da vida, dos valores, dos pontos de chegada, dos objetivos a serem atingidos (em casa e na escola). Dizemos diretamente a elas, ou por meio do contexto, como funciona a linguagem visual, que signos devem ser considerados representativos e quais não. Ficamos ansiosos para fazer com que ultrapassem a etapa das "garatujas" para, então, reconhecer, a partir de seus traços, "as coisas" e as pessoas. E elas acreditam em nós, apoiam-se em nós, imitam-nos.

Grande parte de suas aquisições culturais passam por meio de imagens. Grande parte das imagens passam através dos meios de comunicação. Grande parte dos meios de comunicação instrumentalizam quem os vê com objetivos comerciais. As crianças não entendem facilmente que são plagiadas e, muitas vezes, usadas para fins de lucro. Não entendem que Nasceram para comprar (é o título de um bom livro de Juliet Schor), que sofrem continuamente um Estupro do imaginário (é o título de um bom de Aminata Traoré), que as obriga a se tornarem, cada uma delas, A criança tirana (título de um bom livro de Jirina Prokop).

Se são colocadas lado a lado a necessidade de imitação das crianças e sua instrumentalização, que vem do mercado, teremos crianças com tendência ao conformismo, crianças mimadas, crianças que querem ter mais do que ser (Ter e ser é título do clássico volume de Eric Fromm e, com os verbos invertidos, de um bom filme de Nicolas Philibert). Crianças arrancadas e arrastadas em direção a bens efêmeros, crianças que confundem a realidade com a fantasia (como as crianças italianas que pularam de um armário, porque pensavam que fossem Batman). Crianças, no fim das contas, padronizadas, infelizes e tristes, em busca de um alívio efêmero (um brinquedo, uma roupa de marca, uma comida desnecessária, o celular igual ao dos colegas...). Crianças incapazes de ficarem paradas, pensando e refletindo. O movimento, a corrida, a fuga do real, são o espelho deformado que nós oferecemos às crianças. Ficar em paz, em silêncio, permitir-se uma pausa, tudo isso nós, adultos, transformamos em comportamentos inúteis, até mesmo prejudiciais a elas.

Como podemos pensar que crianças que se refletem nesses espelhos sociais, que nós criamos, possam ser criativas? Claro, crianças muito pequenas, num grande esforço para entender o mundo e a si mesmas, produzem pensamentos e imagens divergentes, não usuais, expressam-se deformando palavras, fazem-nos rir por causa de seus "erros" linguísticos ou lógicos (e não poderíamos sorrir demais na frente de quem está pensando). Mas, lentamente, à medida que elas adquirem gradativamente a nossa linguagem comunicativa, tornam-se cada vez menos originais e menos "desregradas". Quando conquistam nossas regras, tentam não errar, não provocar um "sorriso irônico" que as colocaria em dificuldade e as faria sentir pouco "incluídas". À medida que crescem, as crianças vão tendo mais cuidado para dizer 
o que realmente pensam, ficam satisfeitas em satisfazer-nos, em mostrar-nos sua melhor "cara", aquela mais cuidada, mais semelhante a todos os outros. As crianças não são criativas. Não agora. Não no nosso tempo.

As crianças não são criativas, mas podem tornar-se. A criatividade é uma conquista, um ponto de chegada que não podemos manter para sempre, é uma capacidade precisa, nem sempre afinada. "Al andar se hace el camino. Se hace el camino al andar" (escreve Sepúlveda ${ }^{12}$ ). Caminhando se faz o percurso, o percurso se faz caminhando. A criatividade é uma conquista que se faz ao longo do caminho, é um percurso que não acaba nunca, e que, ao mesmo tempo, encerra-se ali onde estamos. As crianças não são criativas, mas podem tornar-se, se os adultos as ajudarem a tirar a poeira das camadas de sujeira cultural e as crostas dos hábitos estereotipados.

O problema é que nem todos os adultos estão dispostos (ou são capazes) de ajudar as crianças nesse caminho. A formação dos pais e educadores, no setor da educação para a imagem, ainda é muito ligado ao desenho etiqueta, fixou-se em modelos de representação de tipo fotográfico, é mais sensível aos significantes que aos significados. Ensinamos muitas vezes a dizer: "faz-se assim como eu aprendi", em vez de ter confiança no pensamento dos pequenos desenhistas. Em condições mais ou menos normais, toda criança desenha falando, desenha contando ou raciocinando (muitas vezes em voz alta), e - quando está com algum colega - desenha com monólogos paralelos. Ouvir as crianças ou estar disponível para suas narrativas abre uma janela (em direção a um conhecimento complexo) e uma esperança (de criatividade compartilhada), como ocorreu com Enrico (5 anos), que tinha feito um desenho, falando consigo mesmo, e descreveu a um adulto os mecanismos engenhosos que tomaram forma. $\mathrm{O}$ adulto ouve as suas explicações: “... É o relógio do tempo movido a energia supersônica da luz e do escuro... A energia está ligada ao despertador do relógio... A batata dá a energia escura e o sol dá a energia clara... o despertador desliga com os botóes pequenos e liga com as alavancas ... Com o botão grande capta mais energia supersônica e funciona rápido... Mas quando você usa as alavancas podem acontecer coisas perigosas que você não conhece..."

A narração é surpreendente e remete-nos justamente à cultura contemporânea que já é difundida entre crianças pequenas, aquela dos desenhos animados que apresentam sequências cada vez mais velozes, com personagens que usam efeitos especiais movidos a energias supersônicas. O relógio do tempo tem muitos ponteiros porque "funciona rápido, muito rápido" e é movido por dois tipos de energia: a escura e a clara (a batata da energia escura é a forma sinistra com pontinhos). A situação é frenética e dramática (como as histórias de muitos desenhos animados)

12. Sepúlveda, Luis. Patagonia express, 200 I (1995). 


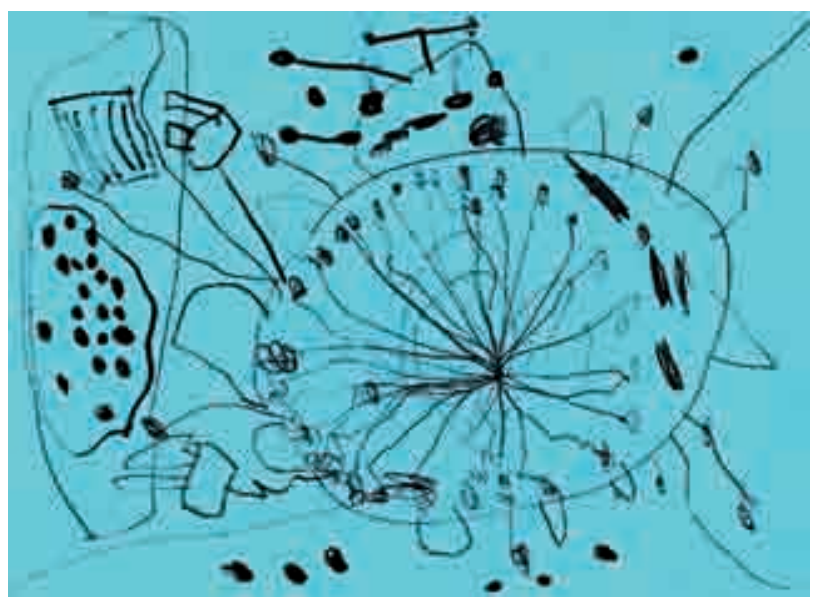

Fig. 6 - Enrico (5 anos): O relógio do tempo

e pode fugir ao controle porque de repente pode aparecer "um perigo que você não conhece".

O adulto comenta, não avalia, escuta e depois reflete em voz alta: "Claro, não é muito cômodo ter um relógio muito rápido; não dá tempo de ir dormir e já é hora de levantar. Não dá para começar um jogo que já é hora de parar e não se pode nem começar um desenho porque o tempo para fazê-lo já passou...”. Enrico olha para o adulto, incrédulo, como se dissesse: "Você não entende" e sai de perto.

No dia seguinte, Enrico procura aquele adulto que o ouviu e que ele ouviu. Entrega um novo desenho. Parecido com o anterior, tem a batata e a energia escura (à direita, embaixo), tem as alavancas e o relógio. Mas as alavancas estão desligadas. Não servem mais. Não servem mais, porque o relógio não tem mais ponteiros, não tem mais pressa. E está feliz, sorri, rodopiando. $\mathrm{O}$ tempo parou.

Os desenhos das crianças são o espelho de seus pensamentos. E os pensamentos refletem, em parte, as sugestôes que as crianças recebem. Em um contexto no qual as mensagens que chegam sempre em maior número e com maior frequência modelam a cabeça segundo a equação "pressa/tecnologia é igual a algo bom", as crianças - que precisam nos imitar - só podem se tornar apressadas habitantes de um universo "superenergético" (embora Enrico intua que possa haver "alguns perigos que você não conhece"). Mas o mito de ir depressa - pelo menos para Enrico, pelo menos desta vez - foi detido pelo prazer de simplesmente ficar parado. O relógio, livre dos ponteiros, sorri. E pede-nos para sorrir com ele. 


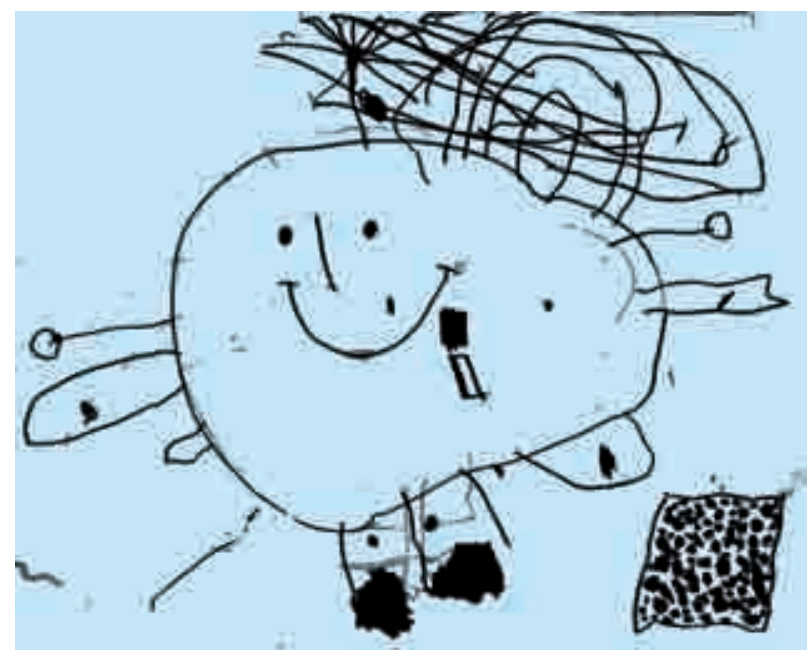

Fig. 7 - Enrico (5 anos): O tempo parou

\section{4 - Comunicar por metáforas}

O caminho privilegiado da criatividade é o caminho da metáfora. Uma vez que é impossível, para todos, representar visualmente a complexidade dos eventos e das percepções por meio de formas bi/tridimensionais, o uso de um instrumento como a metáfora é inevitável. Quando uma mãe italiana canta para o recém-nascido a tradicional canção de ninar que se chama "coxinhas de frango", transmite uma similitude, uma metáfora, e a criança "entende" que ela não é um frango. A metáfora tem justamente o objetivo de "deslocar", "transferir", realizar "transferências de um nome de uma coisa para outra" (Aristóteles). Toda linguagem comum está imbuída de metáforas. Muitas vezes se tornam habituais, transformam-se em "metáforas mortas", desgastadas, catacréticas. Nesses casos ainda servem, comunicam algo, mas não são mais uma mensagem evocadora.

A passagem da metáfora linguística à metafora visual (o visível) é curta. A representação gráfica, assim como a representação linguística, é atravessada por necessidades comunicativas, por exigências de apresentar o mundo e apresentarse a ele. As metáforas linguísticas, quando são ditas pelas crianças, são, talvez, as mais bem recebidas, muitas vezes com um sorriso ou, como diz Bruner, "com uma espécie de sorriso irônico que se exala sempre ao redor da atividade criativa"13. As imagens já são menos bem recebidas; a "correção", o pedido de explicações, o esclarecimento de como se deveriam representar certas coisas sempre intervém nessas imagens...

13. J. Bruner, Il conoscere. Saggi per la mano sinistra, Armando, Roma, p. 4I. 
No âmbito da imagem, é impossível representar visualmente através de formas bi/tridimensionais e estático/dinâmicas, a complexidade dos eventos e das percepções; é impossível dizer "exatamente" o que se quer dizer (quando dizer é lógico-ilógico); e, consequentemente, é inevitável o uso de um instrumento como a metáfora. As metáforas (linguísticas ou visuais, que sejam) são "trocas de pensamentos", são produções abertas e ambíguas que remetem um significado a outro. As metáforas propõem formas surpreendentes, emoções, e não dão respostas. Mostram um fascínio que nos deixa muitas vezes de boca aberta e fazem vir à cabeça a seguinte pergunta: mas como é possível que alguém tenha pensado dessa forma? As crianças assimilam-nas desde pequenas, retomam-nas, consideram-nas um meio normal de contato entre as pessoas. O mundo "não se pode explicar", as experiências, as percepções, as emoções não podem ser transferidas de uma pessoa a outra, a não ser por aproximação.

As metáforas permitem esses deslocamentos, essas aproximações. Uma criança disse, desenhando a mãe e uma caixinha: "Veja, o amor da minha mãe é uma caixinha. Mamãe às vezes abre a caixinha...”. E o que dizer daquela outra menina que recebeu a tarefa da professora de desenhar a mãe e desenhou o sol? É uma menina distraída? Está em conflito com a professora? É uma criança retardada? Nada disso, Luna desenhou um sol porque a "a mamãe está sempre rindo, como o sol".

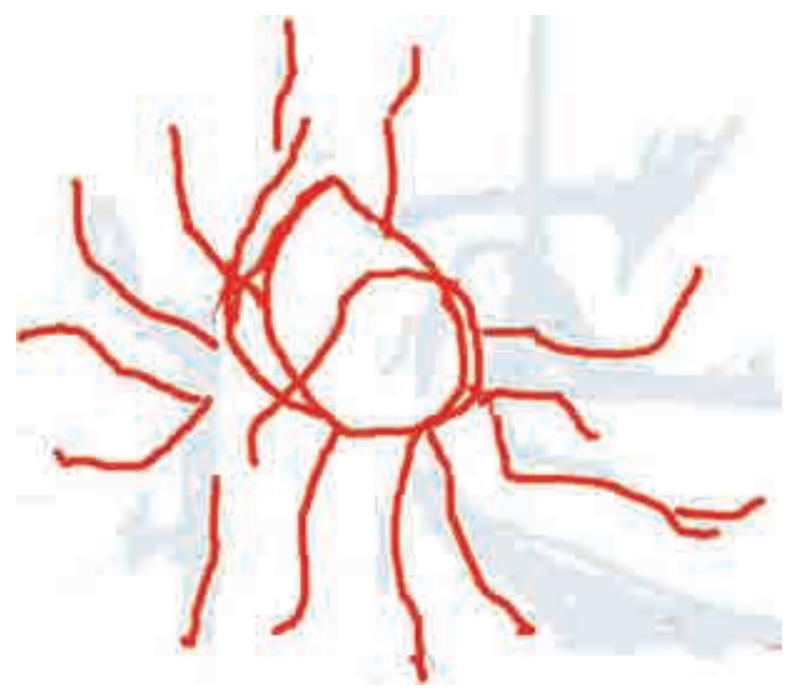

Fig. 8 - Luna (3 anos): Mamãe sol

As crianças que têm dificuldade (elas!) para explicar o mundo, buscam aqueles meios de comunicação acessíveis para elas e os encontram nas metáforas ou, se- 
gundo alguns, nas metáforas "incompletas" (dizemos que são incompletas porque pensamos que as crianças não têm consciência delas). A partir de um ponto de vista didático, é preciso acompanhar, ajudar, apoiar processos metafóricos presentes nas imagens e em todas as comunicaçôes "emocionadas" das crianças.

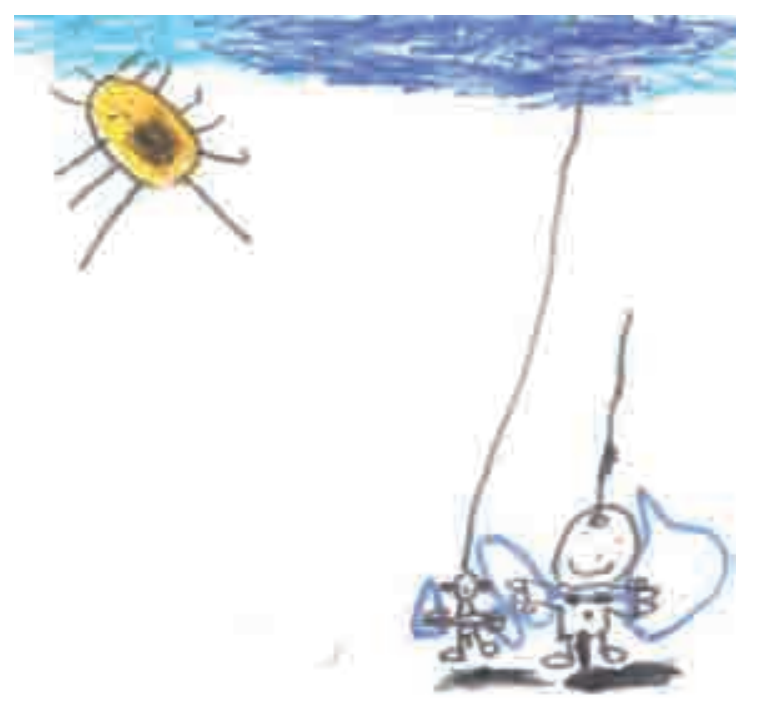

Fig. 9 - Raffaele (5 anos): Somos anjinhos

No desenho de Rafaelle há dois anjinhos que descem do céu (com um fio). Têm asas e um grande sorriso. São dois irmãozinhos, um maior e outro menor. $\mathrm{O}$ episódio é contado por Raffaele, que disse que na ausência do pai, ele e seu irmão tinham "aprontado algumas" (tinham se escondido no quartinho, tinham entrado no escritório...). E, quando o pai voltou, Raffaele estava desenhando e mostrou como tinham se comportado: como dois anjinhos. $\mathrm{O}$ sol, do alto, surpreende-se e sorri... Similitudes e deslocamentos, alusões e inversões, imagens reais e aproximaçōes poéticas... Como no desenho de Umberto de Rovigo, que diz que a noite é negra. É negra como a tinta. A tinta de um tinteiro. A tinta captura a noite... 


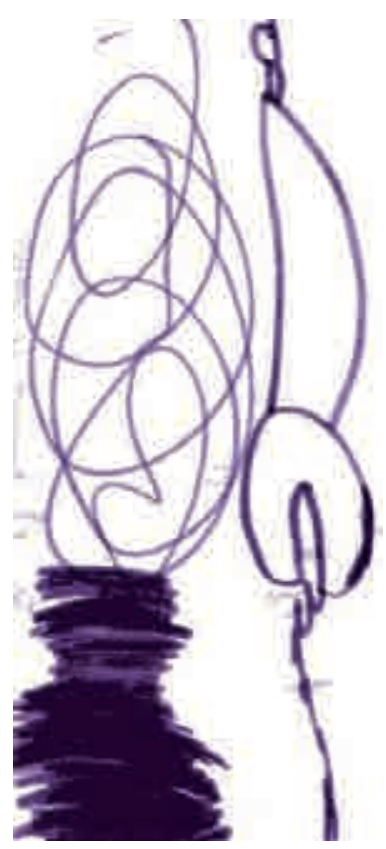

Fig. 10 - Umberto (4 anos): O imã que captura a noite

Para essas crianças (nas idades entre três e cinco anos) é, portanto, possível, natural, expressar-se por transferências. Pode até ser que essas crianças não tenham consciência de estar construindo metáforas visuais e que sua expressão por meio de saltos e deslocamentos tenha ocorrido por necessidade, por inadequação, porque não conseguiam encontrar outro modo para expressar-se. Como pode ser que "seu desenho deslocado" seja simplesmente o reflexo da linguagem dos adultos que, como dissemos, está repleto de metáforas? Mas, justamente, se fosse assim, então, desenhar por metáforas não seria de forma alguma uma exceção, uma especificidade das crianças italianas, mas uma modalidade de comunicação, de interação com o mundo, comum a todas as crianças. Uma possibilidade para o professor e para o educador de observar, não com a ótica do copo que está quase vazio (inadequação metafórica), mas de olhar com o olhar positivo do copo que está meio cheio (uma possiblidade de expressão). Com essa visão e com essa convicção pode ser mais simples intuir as tentativas das crianças e acolher suas necessidades de manter uma comunicação criativa e original com o mundo. A menos que não tenhamos medo de descobrir, como Tomas de Milan Kundera ${ }^{14}$, "que as metáforas são uma coisa perigosa. É melhor não brincar com as metáforas. A partir de uma metáfora apenas pode nascer o amor". Qualquer que seja a forma como for interpretada,

14. A insustentável leveza do ser, p. 19. 
não podemos negar que brincar com as metáforas seja uma boa di-versão, que faz despertar a surpresa em quem a cria e em quem a vê. Como no encontro entre o carteiro e o poeta Neruda no filme homônimo (1994), dirigido por Michael Radford, quando o carteiro Troisi ouve, encantado, uma poesia dedicada ao mar e diz a Neruda que parecia ser "Como um barco açoitado pelas palavras". O poeta olha-o surpreso e lhe diz: "Mas você sabe o que você fez? Fez uma metáfora", O carteiro fica constrangido e justifica-se dizendo: "Não vale porque não queria fazer." Neruda responde: "Querer não é importante porque as imagens nascem casuais." E Troisi: "Então, o mundo inteiro, o mar, com o céu, com a chuva, as nuvens... também podem ser consideradas metáforas de alguma coisa", da existência, talvez. O poeta reflete um momento e depois diz: "Vou pensar nisso. Amanhã eu respondo essa pergunta". Também diante dos pensamentos e das metáforas visuais das crianças não é bom responder logo. É preciso pensar.

Recebido em 22 de dezembro de 2010 e aprovado em 25 de março de 2011. 